ENSAYO

\title{
EL QUIJOTE, CERVANTES Y LOS ENSAYISTAS CHILENOS
}

\author{
Roberto Hozven
}

Relectura de El Quijote de Cervantes a la luz de las alegorías y mitos literarios propuestos sobre la cultura chilena por algunos ensayistas nacionales contemporáneos: desde Luis Emilio Recabarren hasta Sonia Montecino, entre otros. Se resaltan las contraposiciones entre (A) el orden precario y misericordioso del mundo instaurado por don Quijote y las instituciones mentales del huacharaje y del imbunchismo chilenos; (B) la oposición entre autoridad quijotesca y poder dictatorial hispanoamericano; (C) la lectura de El Quijote como mito literario fundador de mitología patria (en España), opuesto al énfasis en la narratividad cervantina como engendradora de libertad crítica (en Hispanoamérica), y, finalmente, (D) El Quijote como ejemplo universal de una actitud narrativa que le abre un hueco a la humanidad y a la sabiduría en este mundo espoleado por los egoísmos y corroído por los deseos.

Roberto Hozven. Profesor titular de literatura hispanoamericana en la Pontificia Universidad Católica de Chile y, entre 1989-1997, en la Universidad de California, Riverside, en EE.UU. Autor de Octavio Paz, viajero del presente (México: Colegio Nacional, 1994), de ensayos, capítulos de libros y artículos críticos publicados en destacadas revistas españolas, hispanoamericanas y norteamericanas. Actualmente prepara un libro sobre ensayistas chilenos contemporáneos.

Estudios Públicos, 100 (primavera 2005). 
$\mathrm{D}$ urante este año conmemorativo del cuarto centenario de El Quijote, alguien me pregunta por su presencia en los ensayistas chilenos contemporáneos ${ }^{1}$. ¿Habrán leído El Quijote efectivamente? ¿Habrán dialogado con él, de alguna manera, en sus ensayos inquisitivos e interpretativos sobre la realidad nacional? ¿Encontramos en los ensayos de Alberto Edwards Vives, de Joaquín Edwards Bello, de Benjamín Subercaseaux, de Luis Oyarzún o — más próximo nuestro- de Jorge Guzmán, de Jorge Edwards, de Marco Antonio de la Parra o de Sonia Montecino, entre otros, algún vestigio de las enseñanzas que nos recuerden los panegíricos de estas efemérides? ¿Como monumento literario de la cultura hispánica, ha significado El Quijote un ejercicio de reescritura para los ensayistas mencionados?

No se trata, por cierto, de levantar un registro de las citaciones o alusiones explícitas al Quijote entre nuestros ensayistas. No; en lo que pienso es en la presencia residual del Quijote como un modelo tácito proveedor de ideas implícitas que atraviesan o no los textos escritos por los ensayistas. Este modelo residual es intangible: lo perciben sólo los ojos que conservan en la memoria las parábolas del Quijote. También recuerda el aura definida por Benjamín: ¿registran los ensayos chilenos las huellas con que El Quijote, un día, los tocó en sus deseos o repudios? Además, el modelo opera de modo transpositivo: las huellas presentes del Quijote en los ensayos pueden ser miméticas o epigonales así como reactivas o defensivas. Desde ese suplemento engañoso que es la connotación (parece que viene después, cuando siempre la entendemos antes de la denotación), los ensayos pueden imitar al Quijote como deformarlo reaccionando contra el modelo mental propuesto por él. Los sentidos de este modelo residual operan, entonces, en un nivel alegórico. Hay alegoría cuando un sentido situado en un nivel explícito remite a una o a más ideaciones implícitas; cuando lo que alguien nos dice, escribe o gesticula genera otros niveles de sentidos remitiendo a otros padrones de ideas que los inmediatamente previstos. Y esto ocurre en todos los registros culturales de nuestra comunicación cotidiana: palabras y gestos exceden la sola representación comunicativa. Cierto, hablamos con la lengua, pero - bien lo sabemos- conversamos con el cuerpo. Y mientras conversamos no cesamos de contarnos todas clases de historias sobre los demás sostenidas por la densidad de sus gestos y actitudes. Así entramos de lleno en el campo de la alegoría, el gran teatro del mundo, el cual, por cierto, comienza por serlo del propio entorno. Y esto nos lleva a la alegoría nacional.

${ }^{1}$ Alusión a mi investigación Fondecyt "El ensayo chileno como forma alegórica de la identidad nacional: 1940-2000", Proyecto No 1980789, desarrollado anteriormente. 
Para el efecto de este artículo, entenderé por alegoría nacional los ensayos y narraciones que, de una u otra manera, representan creencias, imaginarios culturales, supuestamente correspondientes a comunidades étnicas, regionales o nacionales. Estas construcciones imaginarias se sirven de eventos, reflexiones, paisajes o personajes emblemáticos para plasmar mitos fundadores de la nación en diversos niveles: geográficos, históricos, sociales, políticos o poéticos.

Don Quijote, el más famoso personaje literario de la era moderna, es un personaje sin familia. Célibe, sin hijos, encarna al sabio que se ha convertido en padre de sí mismo y maestro de los demás desde sus invenciones letradas. Todo él es un continente escrito que discurre entre la discreción y la locura, "de manera que a cada paso desacreditaban sus obras su juicio, y su juicio sus obras". Como los libros que le alienaron la mente pero no la humanidad, don Quijote interpela a Sancho, a su mundo narrativo y a sus lectores desde un poder autoconquistado: el de alguien capaz de hacerse maestro de sí mismo, de controlar sus emociones con la rienda de sus razones. En este sentido (el romántico de Schiller), don Quijote es sublime: frente a los cataclismos de la naturaleza, las coacciones del destino o las perturbaciones de su propio ser interno, don Quijote arriba, sin embargo, a establecer un orden precario, pero racional, honesto y misericordioso, mediante la farmacopea de su verbo iluminado. Frente a esta primera síntesis humana y familiar precaria, aunque defendida con rotundidad hispánica por don Quijote, nuestros ensayistas nos descubren un Chile en que las instituciones correspondientes ante la práctica utópica del Quijote son el "huacharaje" y el "imbunchismo", tales como las describen Sonia Montecino, Jorge Edwards y Jorge Guzmán, entre otros.

"En los albores del Chile independiente y contemporáneo", no es el padre el núcleo "de la constitución de modelos de identidad genérica sino la gestación de una dominancia de la mujer en la estabilidad de la vida cotidiana" - escribe Montecino en sus Madres y huachos ${ }^{2}$. Esta dominancia resulta de la experiencia del abandono de la mujer y madre por un hombre y padre biológico incapaz de asumir económica y socialmente las consecuencias afectivas y culturales de sus actos. Un efecto de este abandono paternal primario, "la piedra más firme de la identidad popular" (sic) será la camaradería compensatoria que establecen los huachos entre sí: "el huacharaje". Frente a esta alegoría de la dispersión familiar y del resentimiento soterrado, El Quijote, verdadera decisión frente al mundo, propone una alegoría fundadora y ordenadora. Don Quijote está provisto de autoridad,

${ }^{2}$ Sonia Montecino, Madres y huachos. Alegorías del mestizaje chileno (Santiago: Cuarto Propio, 1991), pp. 51, 58. 
en el sentido etimológico de quien introduce, funda y produce un cambio generoso en el mundo mediante la creación de un principio que no existía antes en él ${ }^{3}$. El nuevo principio, propuesto de modo imaginario pero defendido efectivamente por don Quijote, consiste en la formulación de una Justicia trascendente, generosa, que muchas veces tiene que tornarse irónica para adecuarse a nuestro mundo prosaico regido por el disparate. Así me explico el partido tomado por don Quijote, en favor del ardid de Basilio para casarse con Quiteria, en el episodio de las bodas de Camacho (II, 21) o la decisión adoptada por Sancho frente a la aporía que le plantearon los jueces durante el gobierno de su ínsula (II, 51). El principio quijotesco aplicado cristianamente por Sancho para resolver la aporía es digno de ser recordado: cuando la justicia estuviese en duda hay que acogerse a la misericordia.

Por el poder de este mito literario y la trascendencia de sus decisiones, Ramón Menéndez Pidal (junto con la generación del 98) hará del Quijote una metáfora de la nación española por cuanto España habla al mundo a través de él: maestro sabio en sus locuras, ético y honesto en su celibato, capaz de explicar y de otorgarle un orden humano (porque irónico) al caos proliferante del mundo que lo rodea. Don Quijote se ordena y ordena a los demás, incluso a quienes se burlan de él. Se burlan, cierto, pero desde dentro de los mismos parámetros quijotescos: si no, piénsese en la aventura de Clavileño (II, 61). Toda esta escena de crueldad cortesana, donde confluye lo real con lo fantástico, es construida desde la perspectiva mental en que opera el delirio lúcido de don Quijote. Los burladores, para burlarse, asumen los parámetros quijotescos y juegan el juego del burlado. Ante este homenaje invertido, uno se pregunta: ¿quién ríe de quién? ${ }^{4}$

El huacharaje pone en escena un nudo enigmático de la identidad chilena. Este núcleo — creo- reside en la relación psicosocial morbosa que se teje y desteje entre un padre ausente (en su origen el Conquistador español) y la madre (india) abandonada con su prole (mestiza), quien asume un rol compensatorio sobreprotector que termina por abortar la libertad misma de los hijos a quienes protege. Esta relación sobreprotectora produce un hijo huérfano, agradecido a la vez que resentido por la protección materna y quien se pregunta, ansiosamente, por el padre ausente. Su respuesta, su salida ante este laberinto (la sobreprotección castradora de la madre así como el hueco dejado por la ausencia paterna), será la proyección identifi-

\footnotetext{
${ }^{3}$ Emil Benveniste asocia el mismo étimo (augeo) a la "cualidad misteriosa del poder que hace surgir las plantas". Cf. su Le vocabulaire des institutions indo-européennes, Tomo 2 (Paris: Minuit, 1969), 150.

4 "Y dice más Cide Hamete: que tiene para sí ser tan locos los burladores como los burlados que no estaban los duques dos dedos de parecer tontos, pues tanto ahínco ponían en burlarse de dos tontos." (II 70).
} 
cativa con ilusiones heroicas de dominio. Estas ilusiones se proyectan hacia fuera dando origen al despotismo, una de las causas de nuestros caudillismos, y hacia adentro al imbunchismo.

"Imbunche" - según el diccionario de la RAE- es una voz mapuche: "ser maléfico, deforme y contrahecho al que se le descoyuntan los huesos de los hombros, caderas y rodillas". Por extensión, un imbunche es también "cualquier cosa enredada, inextricable, pleito enredado". "José Donoso ha resignificado la imagen del Imbunche y lo ha propuesto como un modo de comprender ciertas características nacionales del encierro, lo contrahecho, lo monstruoso y la manipulación del poder" — escribe Montecino en sus Mitos de Chile ${ }^{5}$. Jorge Edwards nos muestra que el imbunchamiento resulta del proceso larvario, lento, por el que el "orden de las familias" reprime precozmente las inclinaciones profundas, humanas, de sus miembros educándolos en excluyentes prejuicios de clase. El imbunchado es un resultado de las "abuelas bigotudas" - las matronas que gobiernan sus familias con rotunda voluntad absolutista e inquisitorial — así como de un "inútil de la familia" que se esfuerza en la práctica diaria del autodenigramiento porque ya no sabe, ni puede, proceder de otro modo. Lo que al imbunchado le pena es el padre, un padre a quien se teme en lo que se lo ansía: el reconocimiento que no puede dar. Los padres "ningunean" a sus hijos así como ellos mismos fueron abandonados por sus parientes. Este abandono, alegóricamente, también es el de un pueblo distanciado y abusado por sus instituciones; las que deforman simbólicamente a sus ciudadanos, convirtiéndolos en monstruos ${ }^{6}$, para mantenerlos "bajo el peso de la noche". Una de estas monstruosidades en Chile, en el nivel de las relaciones interpersonales, ha sido la manera perversa por la cual nos dirigimos a nuestros superiores: invariablemente los interpelamos sirviéndonos de frases ajenas, que enunciamos como si fueran propias imaginándonos estar en otra parte. Única manera de aproximarnos al aquí y ahora de la interlocución, sabiendo, al mismo instante, que este vaivén enunciativo nos sustrae de cualquier compromiso con la velocidad de un "vacuum cleaner". ¡Cuán lejos estamos del vínculo performativo entre la palabra y la acción quijotescas!; aunque no de Sancho, como bien lo atestiguan los azotes que les inflinge a las hayas en lugar de a sus espaldas (II, 71).

${ }^{5}$ Sonia Montecino, Mitos de Chile. Diccionario de seres, magias y encantos (Santiago de Chile: Sudamericana, 2004).

6 "La ceremonia del Sibillone no es demasiado diferente, guardando las distancias, de la del imbunchismo araucano. El imbunche es el niño más dotado de la tribu, convertido en monstruo a fin de que adquiera poderes de adivinación. Al Sibillone lo transformaban en monstruo durante el espacio de una tarde, pero el episodio quedaba en su memoria marcado a fuego." Jorge Edwards, El sueño de la historia (Barcelona: Tusquets, 2000), p. 131. 
Uno de los substratos made in Chile de la alegoría anterior fue identificado por Alberto Edwards Vives: las polarizaciones y querellas que la Fronda aristocrática tuvo desde siempre con el poder absoluto de los presidentes (poder al que la Fronda siempre se opuso), así como las disensiones facciosas dentro de ella misma, imbuida como lo estaba de "hábitos feudales de dominación e intentos vizcaínos de independencia". Otro substrato es el observado por José Joaquín Brunner: la memoria viscosa que ha anudado en Chile la hacienda con el progreso, la mujer con el hogar patriarcal, la Iglesia con el poder de incidir sobre las costumbres, la ciencia con las verdades dogmáticas, la política con el discurso ritual y la militancia con el sacrificio ${ }^{7}$. Ambos substratos socio-políticos convergen con las instituciones psíquico-culturales del huacharaje y del imbunchismo descritas más arriba. En todos ellos (frondismo, memoria viscosa, huacharaje, imbunchismo) predomina la acción de una voluntad disociativa, autodestructiva, anómica, inspirada por el peor de los sentidos que pueda revestir la política: el de manipular a los hombres para hacerse del poder voluntariosamente. Es muy revelador el sentido etimológico de poder estudiado por Emil Benveniste: tiene poder quien "se hace dueño de él mismo subordinando a un círculo cerrado de personas, de quienes se asume la identidad completa, al punto de resumirla y encarnarla por él mismo". Poder, etimológicamente, es igual a quien representa el papel de "amo, entendido como la unidad social por él encarnada" (op. cit., tomo 1, pp. 91-92). Es decir, estamos hablando de nuestros señores presidentes, dictadores, caudillos, hacendados, abuelas bigotudas, etc. Por supuesto, esta referencia reveladora al étimo de poder nos retrotrae inmediatamente al otro étimo, al que se encuentra en las antípodas del poder: la autoridad, encarnada por don Quijote y Sancho. Ambos no tienen ningún poder porque sólo se representan a sí mismos, viviendo con una sonrisa en la fisura de lo real con lo ideal. Sin embargo, ambos adquieren autoridad al fundar y criticar irónica y textualmente las razones y sinrazones políticas, manipuladoras, desde la racionalidad superior de una justicia distributiva cristiana que castiga y premia dando a cada cual lo suyo de acuerdo a su diferencia. Es lo que ejemplifica el episodio de la liberación de los galeotes (I, 22). Don Quijote y Sancho tienen la autoridad de quienes, de alguna manera, lograron acuñar dialógicamente esa idea de humanidad que Fernando Savater definía como "ese elemento común a partir del cual todos podamos ser, a la vez, semejantes y diversos". Concepto acuñado por la Iglesia Católica y que se remonta a los estoicos ${ }^{8}$.

\footnotetext{
${ }^{7}$ Retomo esta enumeración de J. J. Brunner, Un espejo trizado. Ensayos sobre cultura y políticas culturales (Santiago: FLACSO, 1988), p. 34.

${ }^{8}$ Fernando Savater, Necesidad de la filosofía en un mundo globalizado (Santiago: Presidencia de la República, Conferencias Presidenciales de Humanidades, 2002), p. 33.
} 
Don Quijote es un Bautista de sí mismo: nació como Alonso Quijano, el bueno, y sólo en el itinerario de sus sufridas aventuras se transformó en don Quijote como un hijo de sus propias obras, libre de cualquier deuda o herencia familiar que lo obligue hacia el futuro. Encarna una decisión de raigambre moderna frente al mundo: acuñar su vida de acuerdo a sus propios deseos e intenciones. Bajo esta determinación, don Quijote asume la crítica de la tradición y se convierte en un "inútil exitoso" que se libera, dentro del recorrido de sus dos salidas, del espectáculo prosaico a que lo determinaba su destino de hidalgo empobrecido. Don Quijote afirma el ejercicio de la libertad. Desde la verbal, por medio de lo que Leo Spitzer llamó su perspectivismo lexicológico ${ }^{9}$, a la más universal de cuestionar presupuestos sociales dados como absolutos. "Don Quijote trata de la libertad del individuo para escoger y crear de acuerdo a lo que percibe y siente que es lo verdadero y lo falso" — concluye González Echevarría sintetizando a Spitzer $^{10}$.

Roberto González Echevarría, el gran crítico cubano-americano de la Universidad de Yale, afirma que los escritores españoles de la generación de 1898 (especialmente Azorín, Ramiro de Maeztu y Miguel de Unamuno), en un movimiento que alcanza hasta los estudios de Américo Castro y la novelística de Juan Goytisolo, encontraron la esencia de lo español en don Quijote. Transformaron a don Quijote de mito literario en una mitología patria. El Quijote fue "ungido como vehículo de la quintaesencia misma del idioma y el espíritu de la nación"11. Los escritores hispanoamericanos (Borges y Carpentier específicamente), en cambio, obedeciendo a un profundo deseo de autocuestionamiento, leen y comprenden El Quijote bajo "una ansiedad por indagar sobre su propio oficio e identidad. ¿Cómo reescribir un texto que está esencialmente ligado a la nación que la suya propia luchó por no ser?" (ibíd.). Una vez establecida la distinción, y la razón profunda, del abordaje diferente de El Quijote efectuado por los escritores de este lado del Atlántico, González Echevarría formula su hipótesis central: la condición americana fundamental ¿no tendrá que ver con "la búsqueda de orí-

${ }^{9}$ Cada vez que El Quijote privilegia el denso campo connotativo de la palabra antes que el de la sola denotación lexicalizada: el diálogo lleno de equívocos entre don Quijote y los galeotes (I, 22) o la respuesta de Sancho a la interpelación de Tosilos: "tu amo, Sancho amigo, debe de ser un loco. — ¿Cómo debe?... No debe nada a nadie, que todo lo paga, y más cuando la moneda es locura" (II, 66, yo subrayo).

${ }^{10}$ Roberto González Echevarría en su "Introduction" a Cervantes: Don Quixote. A Casebook, editado por R. González E. (Oxford/New York et alii.: Oxford University Press, 2005), p. 20

${ }^{11}$ Roberto González Echevarría, "Cervantes y la narrativa hispanoamericana moderna: Borges y Carpentier”, Crítica práctica y práctica crítica (México: F.C.E., 2002), pp. 153-154. 
genes que se erigen de forma precaria sobre una ruptura con el pasado, sobre una falla, por así decirlo?” (ibíd.).

Esta hipótesis echa otra luz sobre la diferencia esbozada entre el paternalismo autoritario, pero fundador del Quijote, en contraste con el huacharaje chileno que se gratifica del abandono paterno y de la castración materna ejerciendo un poder despótico sobre los demás, así como severo y cruel contra sí mismos. El Quijote fue precozmente moderno, un self-made man en la península, al alba ideológico-liberal de la narrativa moderna; pero su espíritu libertario, en América hispana, se continuó más a través del género picaresco que del ejercicio crítico ambiguo del voluntarismo utopista de don Quijote. Creo que la autoridad paternal del Quijote y sus acciones consecuentes (en su sentido etimológico de introducir en el mundo un beneficio que allí no estaba) han sido sentidas entre nosotros (más que interpretadas racionalmente) a través de nuestros propios mitos fundadores (huacharaje, imbunchismo). Éstos han distorsionado nuestra percepción del voluntarismo quijotesco al percibirlo a través del tamiz y resabios del poder patrimonialista heredado de nuestro régimen hacendal, y no a través del mejoramiento introducido en la colectividad por alguien que tomó una iniciativa para beneficio y satisfacción de la mayoría. Si la autoridad abre siempre un nuevo camino, eventual y confiable para quienes lo siguen, el poder, por el contrario, fuerza dentro de sus derroteros a adeptos de quienes desconfia. El poder, para perpetuarse, hace de la desconfianza el sistema por el cual controla las eventuales insubordinaciones de sus subordinados. Éste ha sido el poder que ha regido las instituciones mentales y sociales del huacharaje y del imbunchismo y que explica, políticamente, la interlocución enredosa con que abordamos enunciativamente a nuestros superiores jerárquicos. En suma, si el poder es trágico y destructor para quienes lo ejercen por la imposibilidad de controlar y prever racionalmente las fuerzas que en él operan, la autoridad quijotesca, en cambio, reconcilia irónicamente los opuestos en pugna. En Chile — creo- hemos entendido la reconciliación de la autoridad quijotesca como el poder y autoritarismo despiadados (no autoridad) del que se ampararon nuestros caudillos y dictadores. Nuestra lectura de El Quijote - y quién sabe de cuantas otras obras magnas - ha sido desnaturalizada por nuestro "ethos" y práctica cotidiana del poder como maquinación, conversión avasalladora y utilización del otro en nuestro provecho y su autodestrucción. Motivo probable del predominio, entre los ensayistas chilenos contemporáneos, de alegorías nacionales cuestionadoras de cualquier afirmación rotunda del mundo, por más enloquecidamente lúcida, quijotesca, que ésta pueda ser. Habría que especificar, eso sí, la diferencia remarcable que va desde los ensayos de Luis Emilio Recaba- 
rren (Discurso del centenario: ricos y pobres) o de Ariel Peralta (El mito de Chile) a los de Jorge Edwards, José Joaquín Brunner o Marco Antonio de la Parra. Mientras los primeros acuden al ejercicio de una razón antinómica (visible desde el título en el ensayo de Recabarren), que rebate los asuntos criticados por medio de una argumentación tan polarizadora y excluyente como la que cuestionan, los segundos critican el mundo por medio de una razón irónica que también se vuelve contra quien la ejerce. En este sentido, estos últimos serían más cervantistas que quijotistas porque para ellos ha sido más importante la libertad narrativa metadiegética, aprendida en Cervantes, que la historia de los sucesos relatados y vividos por don Quijote y Sancho. Por otra parte, creo que los ensayistas chilenos contemporáneos hacen retroceder el marco mental del narrador cervantino desde el después del cual él enuncia (un viejo mundo relativamente estabilizado en el espectáculo de su mundo prodigioso y lamentable) a la exploración del antes intrahistórico del que emergerán las nuevas realidades humanas y sociales del continente latinoamericano, en ese paréntesis que va desde la Conquista y la Colonia a la Independencia. ¿Cuáles son estas nuevas realidades? El advenimiento de un nuevo sujeto: el mestizo. Una nueva experiencia interactiva: un "ethos" de carácter oral, vital y compartido en una memoria común. Una nueva realidad económica: la hacienda. Así como el paso de una religión "de la palabra" (adscrita lingüística y ritualmente a un sistema conceptual orgánico) a un catolicismo cultual oral, mariano, que no distingue la divinidad de la Virgen María de su intervención diaria en los asuntos y actividades profanos con las cuales se entreteje su figura. Por supuesto, sigo aquí las tesis de Pedro Morandé sobre la emergencia cultural latinoamericana ${ }^{12}$.

Joaquín Edwards Bello, Martín Cerda y Jorge Guzmán son los ensayistas que más enfatizan la suma de marcas culturales de diferenciación con respecto a la sociedad metropolitana y, por cierto, hispánica. Los tres emprenden una tarea "desnaturalizadora" de los referentes culturales con los que operamos. Esto significa que critican dos ideas preconcebidas: que la visión de una cultura y sus textos literarios sea natural, y que el contexto cultural dentro del que vivimos y operamos sea universal y no - como lo es- local y global. Por otra parte, Benjamín Subercaseaux y Luis Oyarzún sienten y expresan de modo más dramático la hipótesis de González Echevarría: de que la búsqueda de orígenes se erigiría sobre una ruptura. Subercaseaux, latamente, habla de fisura. El soporte de la cultura chilena es el

12 Desarrolladas en su Cultura y modernización en América Latina. Ensayo sociológico acerca de la crisis del desarrollismo y de su superación (Santiago: Pontificia Universidad Católica de Chile, 1984). 
"abismo psicológico" entre el conquistador dominante, "sin raíces históricas en la historia del país", y el aborigen que pertenecía a otro ciclo evolutivo. Subercaseaux acuña una imagen sobrecogedora: los europeos construyen una cultura escrita, allegada, sobre una plataforma telúrica hecha de 10.000 años de misterio, amasada por las idas y venidas migratorias de pueblos de cultura oral, de quienes nosotros, hoy en día, desconocemos sus orígenes y destino. Subercaseaux llama "abismo" (a la ruptura de González Echevarría) y escribe su Chile o una loca geografía como una alegoría redentora que impulse a hacerse cargo de esa suma de identidades desdeñadas por la cuña cultural introducida por la Conquista.

En los ensayos de Luis Oyarzún, la ruptura con el pasado se manifiesta como zozobra ambivalente ante la dificultad de encontrar un lugar que concilie la physis (el placer que proporciona la contemplación e inmersión en la naturaleza americana) con la visión orgánica y ordenadora de la cultura en un ámbito moral (tal cual Oyarzún la aprehendía en sus estadías en Europa). Es la desazón que Octavio Paz acusaba como la experiencia típica del habitante del nuevo mundo: "Ser latinoamericano es un saberse ... de esta tierra y de otra tierra. Estamos condenados a buscar en nuestra tierra, la otra tierra; en la otra, a la nuestra"13. En un nivel íntimo, esta desazón sintomatiza una experiencia traumática: la imposible coincidencia de "vivir adentro de mi yo el no yo, y sentir que el yo y el no yo son idénticos, participantes de la misma luz, ... con eso vencería a la historia y sus terrores" ${ }^{" 14}$. El terror ante esta fisura niega una experiencia utópica, fundamental, afirmada a contrapelo por el Quijote: la posibilidad de vivir la realidad del modo más cercano y conforme con los propios sueños y expectativas. La desazón íntima expresada por el ensayo de Oyarzún rechaza la certidumbre de don Quijote, quien pretende, incluso, leer el instante que vive amparado en su creencia sistémica de verdades paralelas, facultado por la ciencia de su época y por los artificios narrativos del traductor Cide Hamete Benengeli. Me refiero, por ejemplo, al episodio de la cueva de Montesinos (II, 23). Los ensayistas chilenos recusarán en sus ensayos, de distintas maneras, la rotundidad de esta certidumbre cervantina, sentida por muchos lectores del Quijote como "el poder casi divino con que el narrador domina su material narrativo", "su actitud incólume y gloriosa frente a los acontecimientos de este mundo". Actitud narrativa en la que Spitzer veía su mayor significancia histórica ${ }^{15}$. Frente a esta experiencia omniabarcadoramente segura, los en-

\footnotetext{
13 Octavio Paz, "El grabado latinoamericano", Sombras de obras (Barcelona: Seix-Barral, 1983), p. 189.

${ }^{14}$ Luis Oyarzún, Diario intimo, edición y prólogo de Leonidas Morales (Santiago de Chile: Universidad de Chile, Departamento de Estudios Humanísticos, 1995), p. 352.

${ }^{15}$ Leo Spitzer, "Linguistic Perspectivism in the Don Quixote", cf. Cervantes, Don Quixote, editado por R. González Echevarría, p. 164.
} 
sayistas chilenos manifiestan la voluntad subliminal de hacer trastabillar la actitud incólume y prodigiosa del narrador cervantino poniendo en abismo su seguridad narrativa.

Por ejemplo, frente a las polarizaciones desmesuradas que desgarraron a la sociedad chilena durante la dictadura, Marco Antonio de la Parra propone que una cura posible ante los binarismos irreductibles estaría en la proposición de terceros términos, por más escandalosos que éstos nos puedan parecer. Así, ante la oposición de Tongoy (playa popular, barata y contaminada) y Puerto Velero (resort mediterráneo construido frente a Tongoy durante el pinochetismo), los que simbolizan modus vivendi absolutamente antinómicos, la solución no está en escoger uno en desmedro del otro. Escoger Tongoy por motivos de corrección política repudiando, por lo mismo, a quienes escogen Puerto Velero; o, escoger Puerto Velero con desprecio social de quienes escogen Tongoy por su pauperismo. No, un asomo de solución estaría en hacer convivir los opuestos sin exacerbarlos: el cuerpo asoleándose en Puerto Velero y el corazón regodeándose en Tongoy ${ }^{16}$. Evidentemente, esta solución metairónica, grotesca, no cabe en el presente espiritual eterno de El Quijote, el que identifica el pasado y el porvenir disolviéndolos en una atmósfera no de este mundo, aunque se refiera a este mundo.

Concluiré evocando - lo que ha sido para mí- una de las más interesantes lecturas del Quijote, junto con la de González Echevarría, por cuanto facilita el establecimiento de ciertas convergencias con los ensayos chilenos a que me he venido refiriendo. Se trata de la "Dulcinea encantada" de Erich Auerbach ${ }^{17}$. Preguntándose sobre el "qué" intrínsecamente cervantino que ordena su obra y, en especial, El Quijote, Auerbach destaca, primero, una actitud hacia el mundo y la narración consistente en el placer de entregarse al sin fondo del ser. La posibilidad de vivir, con sensualidad gozosa a la vez que con orgullo reticente y honesto, el espectáculo prodigioso y lamentable del mundo humano. Segundo: no hay otro orden de realidades aparte del juego. La heteroclicidad y diversidad del mundo sensible hacen imposible la formulación de un orden nítido, abstracto, que pueda esclarecer las ambigüedades del mundo fenoménico. Es imposible fijar o controlar la indeterminación e informidad de lo viviente. Tercero: la locura de don Quijote no es, en realidad, más que una coartada que le permite a Cervantes asumir una actitud narrativa que le abre un hueco a la humanidad

${ }^{16}$ Marco Antonio de la Parra, La mala memoria. Historia personal de Chile contemporáneo (Santiago: Planeta, 1997), p. 241.

${ }^{17}$ Erich Auerbach, "The Enchanted Dulcinea", en Mimesis. The Representation of Reality in Western Literature [1953, $1^{\mathrm{a}}$ ed.] (New Jersey, EE. UU.: Princeton University Press, 1974), pp. 355-358. 
y a la sabiduría, en este mundo de cuerdos espoleado por los intereses y corroído por los deseos. Y aunque don Quijote pague el precio, siendo sucesivamente vapuleado, pisoteado y humillado múltiples veces, sufrirá las vejaciones con una sonrisa, apoyado en su convicción de que "Cada ser es único y cada hombre es muchos hombres que él no conoce" y que, para conocerlos, antes hay que "aprender a ser libre", lo cual implica también "aprender a sonreír"18.

Creo que esta lectura optimista de Auerbach converge con la actitud suscrita por Jorge Edwards, José Joaquín Brunner y Bernardo Subercaseaux, tres ensayistas desmitificadores de nuestra realidad nacional. A la vera mítica de Edipo y de Sísifo, los tres ensayistas nombrados nos proponen una incorporación a la modernidad que va más allá de nuestra habitual apropiación híbrida y realización "pícara"19 de ella. Como Edipo, los tres nos animan a emularlo en el difícil arte de resolver nuestras encrucijadas y polarizaciones trágicas explorando sus escenas originarias. Como el Sísifo de Camus, los tres nos desafían a que transformemos nuestra exasperación (ante una modernidad aplastada por el peso de la noche, por los resentimientos del huacharaje y por los retorcimientos del imbunchismo) en el ejercicio esperanzador de abrirle un hueco a la humanidad y a la sabiduría - como El Quijote - en este mundo de cuerdos espoleado por los intereses y corroído por los deseos. Aunque nos conste que la civilización es el anverso provisorio de la barbarie, emulando al Sísifo de Camus ${ }^{20}$ y al Quijote cervantino, los tres nos insisten en que "todo no es ni ha sido agotado" y que "las verdades prominentes dejan de aplastarnos cuando las reconocemos". Probablemente así podremos asumir nuestra condición latinoamericana humana y moderna, prodigiosa y deleznable, dejando de ser los huérfanos flagelantes y paradójicos cuya única manera de incorporarse al tiempo y espacio de los padres ha sido tornándolos presentes mediante códigos que resaltan su ausencia.

\footnotetext{
18 Octavio Paz, "La tradición liberal" [Discurso en Alcalá de Henares al recibir el premio Cervantes, 23 de abril de 1982], Obras completas 3: Fundación y disidencia. Dominio hispánico (Barcelona/México: Círculo de lectores/ F.C.E., 1994), p. 307.

${ }^{19}$ Una pillería "chilena" de Sísifo, el sabio tramposo: en el momento de su muerte, le pide a su mujer que no le haga fiestas funerarias. Llegado al reino de los muertos, le solicita a Plutón regresar al reino de los vivos para castigar el desacato de su esposa. Una vez fuera del Hades, no cumple su promesa de regresar. Zeus castiga esta pillería condenándolo a "regresar" un peñón, una y otra vez, a su inestable punto de origen. Esta pena convierte a Sísifo en el asalariado permanente de un trabajo inútil y sin esperanza: por toda una eternidad nunca acabará nada. Es el destino explícito de varios personajes chilenos: Joaquín y Francisco, protagonistas y deuteragonistas de El peso de la noche (1965), de Jorge Edwards.

${ }^{20}$ Suscribo la interpretación que hace Albert Camus del mito de Sísifo. Ver El mito de Sísifo. Ensayo sobre el absurdo (Buenos Aires: Losada, 1953), pp. 94-97. La primera frase entrecomillada proviene de este texto; la segunda es mi traducción del original en francés.
} 